\title{
The influence and risk of education platform on middle school students' Education under the background of "Internet + "
}

\author{
Yu-xin XIA ${ }^{1, a}$, Zhi-chen $\mathrm{LI}^{2, \mathrm{~b},{ }^{*}}$ \\ ${ }^{1}$ School of Business Administration, HOHAI University, Changzhou Jiangsu, 213022, China \\ ${ }^{2}$ School of Business Administration, HOHAI University, Changzhou Jiangsu, 213022, China \\ Aemail: xiayuxin1998learn@163.com, bemail: lizhichen1998@163.com \\ *Corresponding author:Zhi-chen LI
}

Keywords: Online education platform; Youth Education.

\begin{abstract}
With the rapid development of Internet technology, the development of online education platform in China has made certain achievements. This document mainly analyzes the impact of online education platform on middle school students' education and the existing risks. The paper collects the feedback of some middle school teachers and students on the use of online education platform through a questionnaire survey, and finds out the development obstacles of online education platform, and finally gives relevant policy recommendations.
\end{abstract}

\section{Introduction}

With the rapid development of Internet communication technology, the education industry is continually innovating and improving the education mode. The traditional education mode organizes classroom teaching in the form of class collectively, and its characteristics of "giving priority to teacher's lecture and assisting students' listening" has exposed obvious drawbacks ${ }^{[1]}$. In response to people's demand for education of higher quality, online education platform supported by Internet technology has developed rapidly in recent years, and has gradually penetrated into preschool education, primary and secondary education, undergraduate and postgraduate education, overseas study, vocational examination and other aspects, involving interest education and comprehensive education in the area of education and training. Compared with traditional schooling, online education breaks the limitation of time and space, which makes educational resources more sharing, and can teach students in accordance with their special aptitude. It has a series of advantages that traditional education does not have and has been widely accepted by parents and students ${ }^{[2]}$. China's "Internet + education" represented by many online education platforms such as MOOC, NetEase open class and Baidu homework team has gradually changed the traditional educational form and created a new pattern of education industry. However, the process of online education platform development is also accompanied by doubts. The low level of teachers, false propaganda, more entertainment functions, content discomfort, unreasonable fees and other public opinions frequently occur, making parents and teachers use online education platform to improve children's academic performance or cultivate children's interests and hobbies, while worrying about whether children will be misled by teachers without qualifications, or induced by some profit-making entertainment information as well; student users begin to question the accuracy of learning resources. Therefore, in-depth investigation of users' feelings about the use of online education platform, questioning the reasons and improving opinions will help to improve the online education platform, consolidate the user groups, and it has important significance to promote the sustainable development of new education model. 


\section{Research objects and research methods}

\subsection{Research objects}

This paper takes middle school students as the research subject, covering more than ten middle schools in Anhui Province and Jiangsu Province, including Hefei No. 1 Middle School, Hefei No. 6 Middle School, Dong Zhi No. 3 Middle School, Taizhou Middle School, Changzhou North Suburb High School, Suzhou Middle School, etc.

It has certain progressiveness to conduct direct research on middle school students. First of all, the education of middle school students is an issue of great concern to the education industry in our country at present. Higher efficiency and high-quality education mode is also urgently needed to improve the rate of enrollment and cultivate high-quality talents. Therefore, the survey results will be more practical. Secondly, the direct beneficiaries of online education platform are mainly middle school students, and the use of online education platform for middle school students, as well as the use of existing related products, to collect subjective information from them, will help the author more accurate and comprehensive analysis. In addition, the author also conducted a targeted questionnaire survey among middle school teachers. Teachers, as traditional classroom instructors, have a direct and relatively professional understanding of the educational outcomes and existing risks of online educational platforms. Collecting opinions of teachers group will help to put forward effective policy recommendations.

\subsection{Research methods and data sources}

This study adopts online questionnaire survey and interview survey method. The questionnaires were directionally delivered to middle school students and junior and senior high school teachers in Anhui and Jiangsu, including Hefei No. 6 Middle School, Hefei Yu Ying School, and Taizhou Middle School and so on. The questionnaires covered all subjects and were representative. Finally, there were 500 questionnaires and 468 valid questionnaires. The applicable rate of the questionnaires was $93.6 \%$.

\section{The impact of online education platform on middle school students' education and the existing risk analysis}

\subsection{The situation and feedback of using online education platform for middle school students}

The results show that the most frequently used online education platforms for middle school students are Homework Help, MOOC, NetEase Open Class and 100 words chopped. Among the students, $70.73 \%$ of middle school students used homework help. The Homework Help platform has abundant question bank resources, and has outstanding advantages in solving difficult problems, searching answers and other functions. In addition, from the types of online education platforms used by students, students tend to use video (represented by MOOC and NetEase Open Course), sound pictures (represented by 100 words chopped, Scallop English) and other multimedia teaching methods.

For the purpose of using online education platform, $73.17 \%$ of the students chose "problem solving" and $65.85 \%$ chose "video course". According to the above-mentioned functions of the online education platform, which is used most by middle school students, the platform's solutions and the development of video course are favored by most students. While there are many kinds of online education platforms with innovative functions, we should also consider that the most important needs of users are the most basic needs. Perfecting the basic functions may attract more users.

\subsection{Situation and feedback of using online education platform for secondary school teachers}

The survey revealed that the number of middle school teachers using the online education platform was significantly lower than that of middle school students, and the frequency of use was also lower. Among the teachers who use the online education platform, the main purpose is to "search for teaching resources to enrich classroom teaching content", "enhance professional knowledge" and answer teaching questions. It can be seen that the use of online education platform for teachers is only 
to search for learning resources and their fundamental purpose is to improve the traditional classroom teaching content. When collecting the risk feedback from teachers, $78.05 \%$ of the teachers said that the self-control ability of middle school students was weak and teachers were afraid that students would be disturbed by other unrelated information when they used electronic devices for self-learning, thus reducing the actual learning efficiency. $64.25 \%$ of the teachers believed that the search question bank function of online education platform would make students depend on the platform and could not train their independent thinking ability. 33.66\% of the teachers believed that the online education platform lacked the interaction between teachers and students compared with the traditional classroom, so it could not achieve targeted teaching.

\subsection{Research conclusion}

\subsubsection{User's tendency towards online education platform}

Problem solving and video courses are a major part of secondary school users' need. The education of middle school students is mainly exam-oriented education, so most users like to use the method of "brushing questions" to improve their skills and achievements. Video courses can play a good preview and review effect. Teacher users tend to integrate the resources of online education platform, and enrich professional knowledge to improve classroom teaching. At the same time, the new functions of online education platform, such as live classroom, online interaction, tailor-made learning plan, are not familiar or loved by most students.

\subsubsection{Considerations on choosing online education platform for middle school students}

The richness of platform learning resources and the quality of teachers will affect user choice to a large extent. Students favor apps with large question banks and fast retrieval, and choose video courses with a strong faculty. Whether most of the topics can be found, and whether a master course is offered, will determine whether the user chooses the platform and how long it will last. In addition, the choice of classmates and the trend of the time will also affect the choice of users.

\subsubsection{Major obstacles to the development of online education platform}

First, coverage and accuracy of platform resources need to be expanded and improved. As a direct impact on the online education platform education and teaching ability of the factors, the integration of the resources of various platforms is not perfect, to the middle school users to access information, to seek solutions to a certain degree of trouble.

Second, self-control ability of middle school students is weak and their learning ability is not strong enough. Parents and teachers of middle school students say that the content of entertainment information displayed on online learning platform will affect learning efficiency, so the promotion of online education platform is opposed by many parents and teachers. The survey shows that only $32.17 \%$ of teachers support students to use online education platform independently.

Third, compared with traditional classroom, teacher-student interaction on online education platform is not muscular enough. It is equally important to collect feedback from students in the process of teaching. But after divorcing from the traditional classroom teaching mode, the education mode under the Internet mostly only has the student independent study link, seldom has the comprehensive feedback to the study result ${ }^{[4]}$. Therefore, the imperfection of targeted teaching represents one of the factors hindering the development of online education platform.

\section{Countermeasures and suggestions}

\subsection{Strengthen the integration of resources, expand the coverage of learning materials and improve the accuracy.}

Through cross platform cooperation to integrate learning resources and enrich the database. Efforts should be done to improve the accuracy of learning resources. We should strive for learning resources from high-quality teachers and improve the quality of learning materials so as to consolidate existing user groups and attract more users. 


\subsection{Enhance publicity for emerging functions.}

Carry out diversified publicity activities to enhance users' understanding of the function of online education platform. To promote users' perceived value of the platform, online publicity such as preferential activities, interesting learning contests and offline teacher-student interaction should be conducted. And pay attention to the current trend of fashion, and carry out continuous reform and innovation.

\subsection{Improve students' feedback functions.}

Add social media to provide a channel for students to communicate with students, students and teachers. In addition, development of personalized learning plate, the development of a characteristic learning program, and learning results for regular acceptance. At the same time, the feedback board of students' parents should be opened to allow parents and teachers to participate in, so as to further enhance the service and interaction of online education platform and achieve the purpose of long-term improvement of learning effect.

\section{Summary}

With the weaknesses of traditional classroom education and the rapid development of Internet technology, the rapid development of online education platform seems to be an inevitable trend. After achieving the stage results, it will be helpful for the flourishing development of the online education industry and the innovative progress of the education industry to recognize the need of the main customers in the market and remove the obstacles hindering the promotion. Although it will not completely replace the traditional form of education in the short term, "Internet + education" will occupy an increasingly prominent position in all fields of education.

\section{References}

[1] Jiang Dacheng, Wang Mingyu, Research on the current situation and Development Countermeasures of online education in China [J], Electronic Commerce, vol.09, pp. 68-69, 2015.

[2] Yan Chunting, Wang Mingyu, Online education, the trend of future education [J], Electronic Commerce, vol.03, pp. 63-64,2016.

[3] Ma Dan, Long Huiyun, Jiang Jichun, Research on the problems of MOOC's development in Colleges and Universities[J], Journal of Heilongjiang college of education, vol.03, pp. 46-47, 2016.

[4] Guan Jia, Li Qitao, Current situation, trend and experience of online education in China[J], China Electronic Education, vol.08, pp. 62-66,2014. 